This item was submitted to Loughborough's Research Repository by the author.

Items in Figshare are protected by copyright, with all rights reserved, unless otherwise indicated.

\title{
Enhanced understanding of risk assessment in police custody in England and Wales using statistical modelling
}

PLEASE CITE THE PUBLISHED VERSION

https://doi.org/10.1016/j.ssci.2019.04.006

PUBLISHER

(C) Elsevier BV

VERSION

AM (Accepted Manuscript)

\section{PUBLISHER STATEMENT}

This paper was accepted for publication in the journal Safety Science and the definitive published version is available at https://doi.org/10.1016/j.ssci.2019.04.006

LICENCE

CC BY-NC-ND 4.0

\section{REPOSITORY RECORD}

Stoneman, Melanie-Jane, Lisa Jackson, Sarah Dunnett, and Louise Cooke. 2019. "Enhanced Understanding of Risk Assessment in Police Custody in England and Wales Using Statistical Modelling". figshare. https://hdl.handle.net/2134/37578. 


\title{
Enhanced understanding of risk assessment in police custody in England and Wales using statistical modelling
}

\author{
Melanie-Jane Stoneman ${ }^{\mathrm{a}}$, Lisa Jackson ${ }^{\mathrm{a}}$, Sarah Dunnett ${ }^{\mathrm{a}}$ and Louise Cooke ${ }^{\mathrm{b}}$ \\ ${ }^{a}$ Aeronautical and Automotive Engineering, Loughborough University, Loughborough, UK \\ ${ }^{b}$ School of Business and Economics, Loughborough University, Loughborough, UK
}

Melanie-Jane Stoneman (Corresponding author)

${ }^{a}$ Aeronautical and Automotive Engineering Department, Stewart Miller Building, Loughborough University, Leicestershire, LE11 3TU

Tel: 01509227244

Email: m.stoneman@1boro.ac.uk

Orcid ID: 0000-0001-7492-3316

Melanie-Jane Stoneman is a PhD student at Loughborough University based in the Aeronautical and Engineering Department and School of Business and Economics.

Professor Lisa Jackson

${ }^{a}$ Aeronautical and Automotive Engineering Department, Stewart Miller Building, Loughborough University, Leicestershire, LE11 3TU

Tel: 01509227276

Email: L.M.Jackson@,lboro.ac.uk

Orcid ID: 0000-0002-7463-2989

Lisa Jackson is a Chair in Risk and Reliability in the Aeronautical and Automotive Engineering department at Loughborough University.

Dr Sarah Dunnett

${ }^{a}$ Aeronautical and Automotive Engineering Department, Stewart Miller Building, Loughborough University, Leicestershire, LE11 3TU

Tel: 01509227258

Email: S.J.Dunnett@lboro.ac.uk 
Orcid ID: 0000-0001-6357-4376

Sarah Dunnett is a Senior Lecturer in the Aeronautical and Automotive Engineering department at Loughborough University.

\section{Professor Louise Cooke}

${ }^{\mathrm{b}}$ School of Business and Economics, Sir Richard Morris Building, Loughborough University, Leicestershire, LE11 3TU

Tel: 01509228058

Email: L.Cooke@,lboro.ac.uk

Twitter: @DrVanvan

Orcid ID: 0000-0001-6155-4339

Louise Cooke is a Chair in Information and Knowledge Management in the School of Business and Economics at Loughborough University.

Declarations of interest: None Funding source declaration: This work was supported by the EPSRC under Grant EP/M507908/1. 


\title{
Enhanced understanding of risk assessment in police custody in England and Wales using statistical modelling.
}

\begin{abstract}
The issue investigated in this paper is the risk assessment of detainees whilst they are booked into police custody in England and Wales. It is estimated that hundreds of thousands of people pass through police custody each year, with each detainee undergoing a risk assessment to establish risk of harm to themselves or to others. However, there has been little research to establish which risk factors identified through the current risk assessment process used within England and Wales have the most impact on risk management. Currently the analysis and evaluation of risk is subjective, based on the custody officer's judgement and experience. Little is known through literature as to which factors are most influential in this risk assessment process. This paper highlights these gaps in the process and identifies the driving factors in decision making around detainee risk in an attempt to understand the risk management process better before detailing what further research can be conducted to close the gap in the process. Multivariate analysis was carried out on a data-set comprising of custody record data from three police forces, in particular information recorded as part of the risk assessment. Logistic regression, decision tree and discriminant analysis methods were used as all have the ability to classify and predict. Comprehensive analysis and augmentation of results has determined a set of variables which had an influencing impact on observation level. These results provide the background to the development of a supportive and robust risk assessment tool.
\end{abstract}

Keywords: risk assessment; risk analysis; police custody; multivariate analysis

\section{Introduction}

The purpose of this paper is to use data from police custody records to identify through quantitative methods which factors are most influential in assessing risk of harm and determining the observation level detainees are placed on. In England and Wales when a person is booked-into custody they are assessed for risk of harm to themselves and others and placed on one of four predefined observations levels set out in Table 1. As well as there being a legal requirement for custody officers to carry out this risk assessment (UK Parliament, 1984, Home Office, 2017) there is also an organisational responsibility to ensure the safe detention of a person (UK Parliament, 1998, UK Parliament, 2007). The first national risk assessment guidance was produced in 2000 (Police Leadership and Powers Unit, 2000), with advice since evolving to incorporate recommendations following investigations into deaths in custody (Havis, 2003, Best, 2004, Hannan et al., 2010). The increasing robustness of the risk assessment has been acknowledged as a contributing factor into the reduction of deaths in custody in recent years (Angiolini, 2017). Since 2004/05 when the Independent Police Complaints Commission began recording the figures, the number of deaths in police custody has fallen from 36 to 14 in 2016/17. Although, the number of these deaths increased to 23 in 2017/18, only 8 occurred after the detainee became unwell in a police cell, the remainder occurred elsewhere, such as at the scene of arrest or in a police vehicle. 
There has been little research into identifying the main factors that custody officers use to assess risk, and the impact they have on the observation level set. Understanding this element of the process better is the first step in making the process more robust, which would in turn improve detainee safety but also mean more efficient use of resources.

Table 1. Observation Levels as set out in the Authorised Professional Practice guidance (College of Policing, 2017)

\begin{tabular}{ll}
\hline Observation Level & Requirements \\
\hline Level 1 - General observation & Minimum acceptable level of observation. \\
& Detainee is checked hourly \\
\hline Level 2 - Intermittent observation & $\begin{array}{l}\text { Minimum level of observation for detainees under the } \\
\text { influence of alcohol and/or drugs. } \\
\text { Detainees visited every } 30 \text { minutes and roused }\end{array}$ \\
\hline Level 3 - Constant observation & $\begin{array}{l}\text { Used when there is a heightened level of risk. } \\
\text { Detainee under constant observation (usually through CCTV) } \\
\text { and visited every 30 minutes. } \\
\\
\text { Detainee reviewed by a healthcare professional. }\end{array}$ \\
\hline Level 4 - Close Proximity & Used for detainees at highest risk of harm. \\
& Detainees are physically supervised in close proximity \\
& Detainee reviewed by a healthcare professional. \\
\hline $\begin{array}{l}\text { In addition, some forces separate out detainees who require rousing and may also include a 15 minute check category, } \\
\text { referred to as Level 2+ in this paper. }\end{array}$
\end{tabular}

To understand risk assessment, the term 'risk' must first be defined. Quantitative risk is often defined as the likelihood of occurrence multiplied by the severity of consequences. However, when it comes to qualitative risk there are many definitions, as set out in the glossary produced by the Society for Risk Analysis (SRA) (Society for Risk Analysis, 2015). Here, risk is defined as 'the possibility of an unfortunate occurrence', which in the police custody setting would be the possibility of harm to the detainee or others. Risk assessment is defined by the SRA as a "systematic process" which identifies "risk sources, threats, hazards and opportunities", understanding what causes them to occur, their consequences and the significance using "the best available data, information and knowledge, within the constraints and frames of the assessment" (Society for Risk Analysis, 2017). Throughout the work presented here, risk assessment in police custody refers to the process completed during booking-in which assesses the detainee for risk of harm. The outcome of a risk assessment is the decision of whether the risk is acceptable, and if not, how best to manage it to make it acceptable (Pasman et al., 2017). In the case of police custody this would include which observation level to place the detainee under as well as whether to refer them to a Healthcare Professional or mental health services. As part of standardised principles and guidelines for risk management, the British Standards Institute published the risk management model shown in Figure 1 (The British Standards Institute, 2010). 


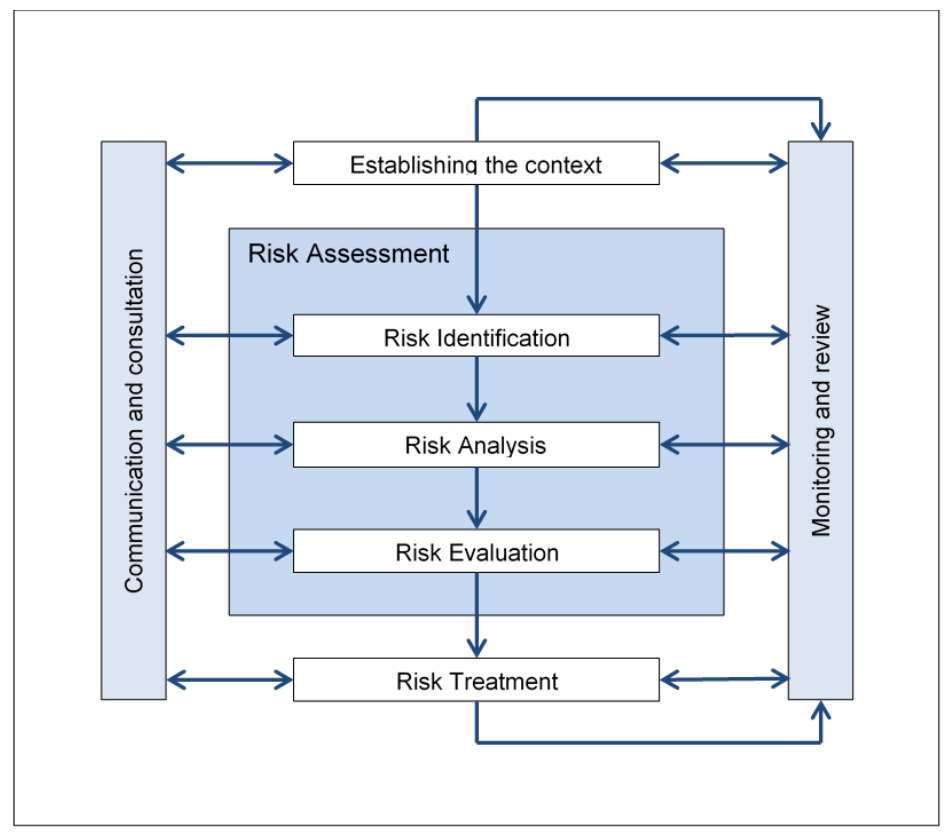

Figure 1. Risk Management Process, BS ISO 31000:2009 (The British Standards Institute, 2010, p vii)

The model identifies three elements to the risk assessment process:

- Risk identification: where sources of risk, their causes and impact are identified;

- Risk analysis: to understand further the causes, likelihood and consequence;

- Risk evaluation: where the level of risk is compared to tolerance levels and the need for risk treatment is considered.

The risk assessment process in police custody revolves around a set of questions to ask the detainee about their health and wellbeing, supplemented by observations the custody officer makes about the detainee. The questions provided in national guidance are shown in Table 2.

Table 2. Risk assessment questions from the Authorised Professional Practice guidance (College of Policing, 2017, n.p.)

\section{Main questions to be asked:}

- How are you feeling in yourself now?

- Do you have any illness or injury?

- Are you experiencing any mental ill health or depression?

- Would you like to speak to the doctor/nurse/paramedic?

- Have you seen a doctor or been to a hospital for this illness or injury?

- Are you taking or supposed to be taking any tablets or medication?

- Are you in contact with any medical or support service?

- Do you have a card that tells you who to contact in a crisis?

- Have you ever tried to harm yourself?

\section{Supplementary Questions:}

- What is the name of your GP and GP's surgery?

- Do you have a family member who is aware of your health problem?

- Is there anything I can do to help? 
Comparing the process in police custody with the risk management model outlined in Figure 1, shows that the questions and observations are used for risk identification, however, currently there is little structured guidance or knowledge on how the risk analysis and evaluation is conducted. The custody officer's use their own decision-making skills to analyse and evaluate what they consider the level of risk to be. This gap in the process means that the decision is based on the experience and tacit knowledge (Polanyi, 1958) of the custody officer. This leads to subjective decision-making where individuals will weigh risk factors differently and include additional influences that others may not (Durodie, 2017).

The goal of this research is to develop an evidence-based path linking identification of risk through to risk management based on current practice. Whilst it is acknowledged that assessing and calculating risk is often surrounded by unknown factors which have not or cannot be taken into account, meaning that accuracy cannot be guaranteed (Kemshall, 1999), the aim is to understand the risk assessment process as accurately as possible with the given knowledge at hand. Currently, there is little empirical evidence as to the effectiveness of the data collected during risk identification in being able to predict risk of harm, or which factors have the highest weighting. In fact, recent research has shown that what is actually included in the risk assessment varies from the questions in Table 2 and from force to force, with police forces adding their own questions to supplement the guidance (Stoneman et al., 2018) suggesting that forces do not feel the guidance is identifying risk appropriately. An example of this is around alcohol consumption, which is not included in the guidance as a question, yet the majority of forces ask questions around this (Stoneman et al., 2018).

Some empirical evidence as to potential risk factors and indicators is provided through reports investigating deaths in custody. Alcohol and / or drug use has been involved in over $80 \%$ of deaths in custody, either linked through recent consumption or intoxication, or was a contributing factor to their death (Lindon and Roe, 2017). Alcohol consumption can also lead to a delay in identifying risky health conditions such as head injuries. Severe mental health problems are a risk factor and $7 \%$ of deaths between 2004/05 and 2014/15 were of detainees arrested under the Mental Health Act 1983 (Lindon and Roe, 2017). The number of self-inflicted deaths in custody has reduced over the years (IOPC, 2018) but there are no published figures on the number of self-harm incidents in police custody. There have been two recent studies looking at this issue. One study investigated 'near misses' or incidents that could have resulted in the serious illness or self-harm of a detainee, which were reported by the Forensic Medical Examiner (Bucke et al., 2008). The other study investigated the number of self-harm incidents recorded in custody records (Cummins, 2008). The study by Bucke et al estimated that there were around 1,000 near miss incidents a year across England and Wales, of which $40 \%$ may have resulted in death if intervention had not occurred (Bucke et al., 2008), whilst the other study found around 20 self-harm incidents a month in one police force (Cummins, 2008). Another risk factor is the use of restraint which was recorded as a cause of death in around $10 \%$ of deaths over a ten-year period between 2004/05 and 2014/15 (Lindon and Roe, 2017), although this proportion may be higher as it cannot always be proven if the use of restraint was a direct contributory factor (IOPC, 2018). These reports highlight alcohol and/or drugs, mental health and restraint as high-risk factors, however half of deaths in custody are due to natural causes (Lindon and Roe, 2017). This ties in with research that shows detainees generally have a higher level of morbidity than the general population with a large range of mixed diseases and pathology (PayneJames et al., 2010) and between $42-54 \%$ of detainees are already on medication (Payne-James et al., 
2010, Sondhi and Williams, 2017). This paper uses statistical modelling methods to assess the impact of these risk factors on the detainee risk assessment process and the setting of observational levels in police custody.

\section{Methodology}

Three multivariate modelling methods have been chosen: logistic regression; decision trees; and discriminant analysis. Logistic regression is a common method of establishing risk factors where the dependent variable is categorical. Examples of its use include the construction of the offender assessment system (OASys) violence predictor used by the probation services in England and Wales, where risk factors were fitted using a logistic regression model to predict recidivism levels (Howard and Dixon, 2012), and a study to identify significant factors which would predict adolescent behavioural risk (Peng and Nichols, 2003). Decision trees are another classification modelling method that can be used for prediction. The classification ability of this method has been used to create a tool for assessing risk of violence (Monahan et al., 2000, Steadman et al., 2000), as well as in the development of the Harm Assessment Risk Tool used by Durham Police to assess risk of reoffending (Oswald et al., 2017). Discriminant analysis is a less common method used in recent literature, although like the other two methods it has the ability to classify individuals into groups and identify factors that have a significant impact, for example in investigating significant factors in predicting violent recidivism of mentally disordered offenders (Harris et al., 1993). These three methods were selected for their ability to classify and predict whilst using different methodology. This enabled the results from the models to be cross-checked with each other and provide a core set of factors that have the most impact on observation level.

\subsection{Custody Record Data}

Custody record data was collected from three police forces across England and Wales and covered the six-month period from January to June 2016. Overall there were 421 individual custody records with 23 variables, including the dependent variable of Observation Level. These are shown in Table 3. Initial analysis was carried out to establish which variables had a significant association with Observation Level with the null hypothesis that there was no evidence of association. This was carried out using Chi-Square Test for Association for categorical variables, and analysis of variance (ANOVA) for continuous variables using IBM SPSS Statistics 23 (IBM Corp., Released 2015). An initial significance level of $p<0.25$ was applied as recommended by Hosmer and Lemeshow (2000) to capture variables that influence or are influenced by other variables. Table 3 indicates those variables with a significant association and were used in the subsequent multivariate analysis methods.

The dataset had a large proportion of missing data. Where possible, the missing data was input using prior knowledge, for example if the detainee had reported no illness or injury, then 'no' was input into the custody officer observation of illness or injury variable. After this process, the final dataset consisted of 259 records. The ratio of cases to independent variables met the recommended level of 10:1 for logistic regression ((Hosmer and Lemeshow, 2000), but was below the suggested ratio of 20:1 for discriminant analysis (Spicer, 2004). This should be considered when interpreting the data. 
Table 3. Variables included in the custody record data

Demographic \& Socio-

economic

Gender

Age *

Ethnicity *

Employment

Offence Detainee Reported

Offence

Arrival Time

Day of Week

Medical History*

Current Illness or Injury *

Mental Health Problems *

Self-Harm *

Current Feelings *

Drug Use *

Alcohol Use *

Substance Dependency

Alcohol Dependency *
Custody Officer Observations

Straight to Cell

First Time in Custody *

Current Illness or Injury *

Self-Harm *

Alcohol Influence *

Drug Influence*

Behaviour / Demeanour*

* Indicates variables that had a significant association with Observation Level

Table 4 shows the breakdown of custody records by Observation Level. Due to the low number of records in the high-risk categories of Constant Observations and Close Proximity, the group was combined with the next highest category ( $15 \mathrm{mins} \&$ rousals) to create a high-risk group called '15mins + '.

Table 4. Number and percentage of custody records by Observation Level

\begin{tabular}{lll}
\hline Observation Level & $\mathbf{N}$ & $\mathbf{\%}$ \\
\hline 60 mins (Level 1) & 51 & 19.7 \\
30 mins (Level 2) & 147 & 56.8 \\
15mins + (Level 2+, 3 \& 4) & 61 & 23.5 \\
$\quad \begin{array}{l}\text { 15mins \& Rousals (Level 2+) } \\
\text { Constant Observations \& Close } \\
\text { Proximity (Level 3 \& 4) }\end{array}$ & 13 & \\
Total & $\mathbf{2 5 9}$ & $\mathbf{1 0 0 . 0}$ \\
\hline
\end{tabular}

The multivariate analysis was also carried out using IBM SPSS 23 (IBM Corp., Released 2015). Crossvalidation of the model's classification ability was carried out using the standard method within each procedure. As this analysis is exploratory and focuses on identifying the risk factors with the most impact on Observation Level, a more robust method of cross-validation has not been carried out. However, as an additional basic measure of classification accuracy, the proportion of cases correctly classified were assessed as to whether they met the criteria of being $25 \%$ greater than the "by chance alone' proportion (White, 2013) as calculated in Equation 1.

$$
C_{\text {pro25 }}=\left(x_{1}^{2}+x_{2}^{2}+\cdots x_{i}^{2}\right) * 1.25
$$

Where $\mathrm{x}$ is the group proportion and $\mathrm{i}$ is the number of groups.

\subsection{Logistic Regression}

Logistic regression is used when the variable of interest, or dependent variable is categorical in nature. Logistic regression maximises the joint likelihood of the data and predicts the probability of the dependent variable by estimating regression coefficients (Norusis, 1999). There are three main methods: binomial logistic regression is used when the dependent variable is dichotomous, for example a yes or no grouping; multinomial logistic regression is used when the dependent variable has more than two categories; and ordinal logistic regression is used when the dependent variable is 
ranked. The multinomial method has been used here as fitting the model using the ordinal method did not meet the assumption of parallel lines, that the relationship between the independent variable and the logits are the same for all logits.

A logit (g) is the log odds of an event occurring and in a simple binomial regression is expressed as:

Equation 2

$$
\begin{gathered}
g(x)=\ln \left(\frac{p_{x}}{1-p_{x}}\right) \\
=\beta_{0}+\beta_{1} x_{i}
\end{gathered}
$$

Where $p$ is the probability of the event, $\beta_{0}$ and $\beta_{1}$ are coefficients, and $i$ is the number of independent variables. With the multinomial regression model each logit compares the probability of being in the chosen category with the probability of being in the reference category. Therefore, a simple multinomial regression model can be expressed as

$$
\ln \left(\frac{\pi_{i}^{k}}{\pi_{i}^{0}}\right)=\beta_{0}^{k}+\beta_{1}^{k} x_{i}
$$

Where $k=1,2, \ldots, \mathrm{K}$ number of categories and $\pi^{0}$ is the probability of the chosen reference category, with K-1 logits being calculated. Maximum likelihood calculations are then used to estimate parameters.

A backward stepwise method was used to build the model and the reference category was the 60 mins group. The full model was fitted and variables were removed and re-entered based on their Likelihood Ratio Test significance ( $p>0.1$ and $p<0.05$ respectively). The variables remaining in this model were then assessed for interactions in a similar way. Classification accuracy was assessed by cross-classifying the observed value with the predicted group membership.

\subsection{Decision Trees}

Key uses of decision trees are for variable selection and prediction (Song and Lu, 2015). Decision trees provide a graphical representation of the classification model which is often easy to interpret (de Oña, 2013). It is a non-parametric method which does not assume a normal distribution and can therefore handle different data types and complex datasets, although this has the potential to lose information and be less accurate than other models (Adams and Leveson, 2012).

Decision trees are grown by recursively partitioning the target variable, splitting the data into subgroups based on the independent variables (Adams and Leveson, 2012). The decision tree can then be easily translated into a series of IF, THEN, ELSE rules (de Oña, 2013). In this current paper the method of Chi-Squared Automatic Interaction Detection (CHAID) was used to build the tree. CHAID uses a chi-square calculation to identify the independent variable with the most significant link with the dependent variable (IBM, 2013). This can be carried out using either Pearson's ChiSquare statistic or Likelihood Ratio method. The model in this paper uses the Likelihood Ratio method as it is seen to be more robust in the way small samples are handled (IBM, 2013). Elements of the tree such as depth and significance level for splitting can be controlled. 
Cross-validation was conducted using the procedural method of creating subsamples of data.

Decision tree models are then created excluding the subsamples of data in turn. The subsamples are then applied to the model that excludes this data and assessed for accuracy (IBM, 2013).

\subsection{Discriminant Analysis}

Discriminant analysis can be used to classify and predict an individual case into a group based on known information. The method is parametric and uses linear combinations of predictor variables to maximise between group variance in relation to within group variance. Therefore, categorical variables should be recoded into dichotomous or dummy variables before analysis to provide a linear relationship with the dependent variable (Tabachnick and Fidell, 2001).

Discriminant coefficients are calculated which maximise the sum of squares ratio, or eigenvalue. Coefficients for independent variables are then multiplied by an individual's score for that variable producing a discriminant score (Spicer, 2004). This can be expressed as:

$$
D=v_{1} X_{1}+v_{2} X_{2}+\cdots+v_{i} X_{i}
$$

Where $v$ is the discriminant coefficient, $\mathrm{X}$ is the individual's score for that variable, and $\mathrm{i}$ is the number of predictor variables. This score is then transformed into a probability giving the likelihood of the individual case belonging to a group.

There are $\mathrm{n}-1$ discriminant functions, where $\mathrm{n}$ is the number of groups. The first function accounts for the majority of variance. The following functions account for a reducing amount of variance and are based on assumptions not used in the preceding functions (Tabachnick and Fidell, 2001).

As with the logistic regression model, a backward stepwise method was used to build the model using a significance level of $p>0.1$ to remove independent variables and $p<0.05$ to re-enter variables into the model. Prior probabilities were used in calculating classifications as the proportional split between groups was not assumed to be equal. The procedures cross-classification method of 'leave one out' was used to measure classification accuracy.

\section{Results}

This section provides the results from applying the three multivariate analysis methods described in section 2 to the custody record data. These findings are then compared and contrasted in section 3.4. Due to the nature of the analysis methods variables with more than two categories were recoded into dummy variables. For example, the variable Offence was coded into 4 dummy variables, of which Miscellaneous or Sexual Offences was the only one to be found to be significantly associated with Observation Level. The category of Miscellaneous includes arrests for Breaches of Order, Bail Act and Molestation.

\subsection{Multinomial logistic regression}

Table 5 shows the significant independent variables after conducting the multinomial logistic regression analysis, along with the chi-square value, degrees of freedom and associated significance. 
Table 5. Logistic regression model variables including two-way interactions

\begin{tabular}{|c|c|c|c|c|}
\hline Independent Variable & $\begin{array}{l}-2 \text { Log Likelihood of } \\
\text { Reduced Model }\end{array}$ & Chi-Square & Df & Sig. \\
\hline Intercept & 115.901 & .000 & 0 & . \\
\hline Observed Alcohol Intoxication & 149.566 & 33.665 & 2 & .000 \\
\hline Miscellaneous or Sexual Offence & $115.901^{\mathrm{a}}$ & .000 & 0 & . \\
\hline Reported Alcohol Consumption & $115.901^{\mathrm{a}}$ & .000 & 0 & . \\
\hline Reported Drug Use & $115.901^{\mathrm{a}}$ & .000 & 0 & . \\
\hline Reported Feelings & $115.901^{\mathrm{a}}$ & .000 & 0 & . \\
\hline Report Injury or Illness & 127.996 & 12.095 & 2 & .002 \\
\hline Reported Mental Health Issues & 139.724 & 23.823 & 2 & .000 \\
\hline $\begin{array}{l}\text { Miscellaneous or Sexual } \\
\text { Offence*Reported Alcohol } \\
\text { Consumption }\end{array}$ & 130.678 & 14.777 & 2 & .001 \\
\hline $\begin{array}{l}\text { Reported Drug Use*Reported } \\
\text { Feelings }\end{array}$ & 126.258 & 10.357 & 2 & .006 \\
\hline
\end{tabular}

Table 6 shows that the fit of the model is adequate, with a significant Likelihood Ratio Test and a Nagelkerke statistic of 0.628 , which suggests that $63 \%$ of variance is explained by the model. Both the Pearson Chi-squared and Deviance statistics are showing as not significant indicating that the model is a good fit. However, it is acknowledged that these statistics are not reliable when there are a large number of cells with zero value, as is the case with the dataset used.

Table 6. Logistic regression model fitting information

\begin{tabular}{llllll}
\hline & Chi-Square & df & Sig. & \multicolumn{2}{l}{ Pseudo R-Square } \\
\hline Likelihood Ratio Test & 193.189 & 18 & 0.000 & Cox and Snell & 0.540 \\
Pearson & 74.535 & 92 & 0.908 & Nagelkerke & 0.628 \\
Deviance & 62.189 & 92 & 0.993 & McFadden & 0.396 \\
\hline
\end{tabular}

Table 7 shows the number and proportion of observed cases and their predicted group. Overall, $73 \%$ of cases were correctly predicted by this model, increasing to $75 \%$ for the high-risk group of $15 \mathrm{mins}+$ and $89 \%$ for 30 mins, however only $25 \%$ of the 60 mins group were correctly classified.

Table 7. Logistic regression classification statistics

\begin{tabular}{lrrrr}
\hline & \multicolumn{4}{c}{ Predicted } \\
Observed & 60 mins & 30 mins & 15 minst & Percent Correct \\
\hline 60 mins & 12 & 34 & 2 & $25.0 \%$ \\
30 mins & 2 & 126 & 14 & $88.7 \%$ \\
15 mins+ & 0 & 15 & 44 & $74.6 \%$ \\
Overall Percentage & $5.6 \%$ & $70.3 \%$ & $24.1 \%$ & $73.1 \%$ \\
\hline
\end{tabular}


Using the formula set out in Equation 1, $C_{\text {pro25 }}$ can be calculated as $\left(0.193^{2}+0.570^{2}+0.237^{2}\right) * 1.25=$ 0.523 . This suggests that to be $25 \%$ better than the 'by chance' proportion, the classification accuracy should be greater than $52 \%$, which it is.

\subsection{Decision trees}

The decision tree was created from fitting the model using the CHAID method with a significance of $p<0.1$ for splitting data and a depth of 5 . The tree is shown in Figure 2.

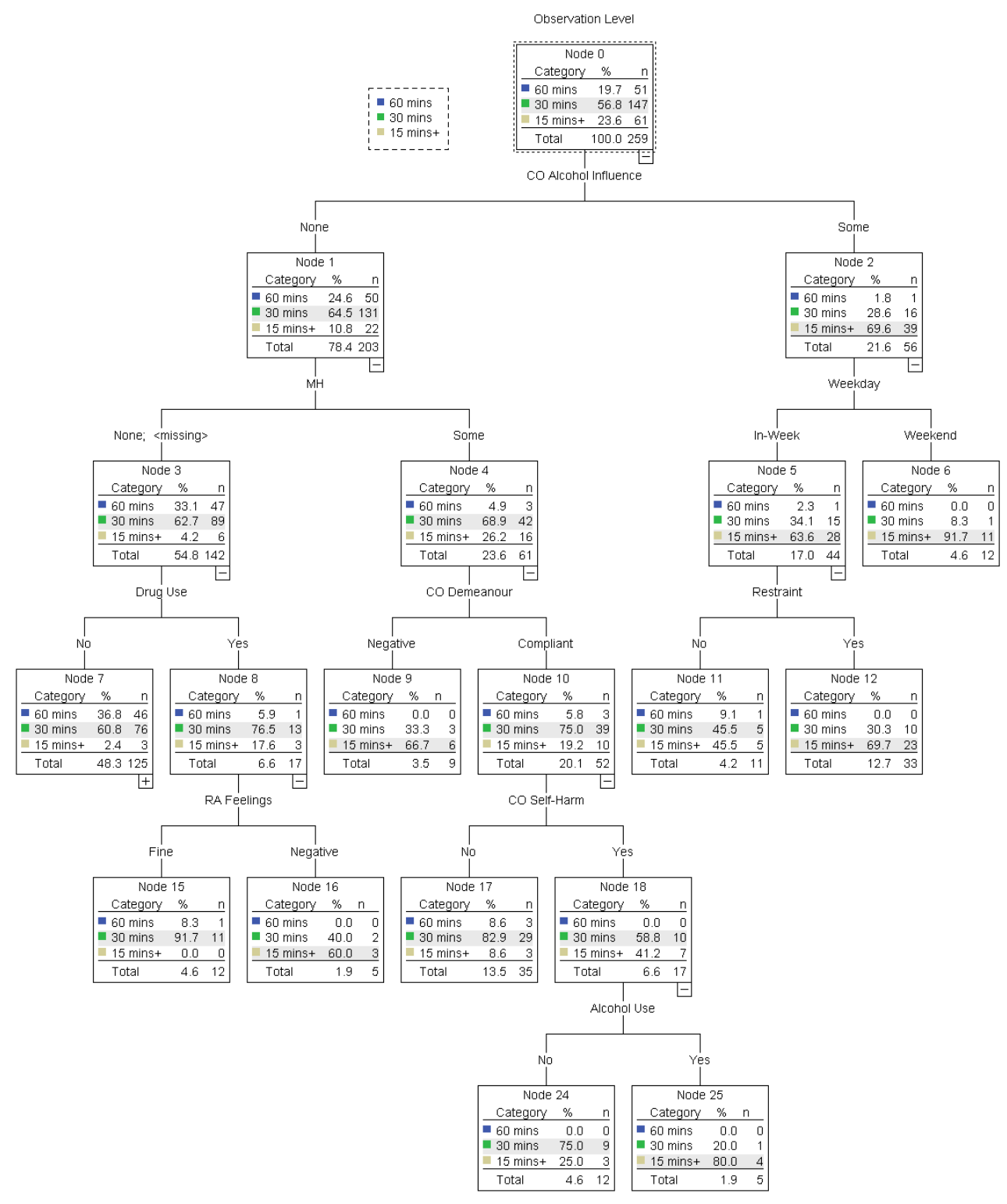

Figure 2. CHAID Decision tree

Table 8 shows the 'risk' statistic for the decision tree. The risk is the amount of variance that is not accounted for by the model. This suggests that $27 \%$ of variance is unaccounted for, which in turn suggests that $73 \%$ of variance is accounted for. 
Table 8. Decision tree risk statistics

\begin{tabular}{lrr} 
Method & Estimate & \multicolumn{2}{c}{ Std. Error } \\
\hline Resubstitution & .270 & .028 \\
Cross-Validation & .359 & .030 \\
\hline Growing Method: CHAID & &
\end{tabular}

The number and proportion of cases by observed and predicted group membership are shown in Table 9. Overall, the model correctly classified $73 \%$ of cases, increasing to $77 \%$ for the $15 \mathrm{mins}+$ group. The proportion correctly classified in the other groups was also relatively high with $69 \%$ for 60 mins and $73 \%$ for 30 mins. The $C_{\text {pro25 }}$ statistic for this model is 0.520 , which is lower than the classification proportion.

Table 9. Decision tree classification statistics

\begin{tabular}{lrrrr}
\hline & \multicolumn{4}{c}{ Predicted } \\
Observed & 60 mins & 30 mins & 15 mins+ & Percent Correct \\
\hline 60 mins & 35 & 16 & 0 & $68.6 \%$ \\
30 mins & 23 & 107 & 17 & $72.8 \%$ \\
15 mins+ & 0 & 14 & 47 & $77.0 \%$ \\
Overall Percentage & $22.4 \%$ & $52.9 \%$ & $24.7 \%$ & $73.0 \%$ \\
\hline
\end{tabular}

\subsection{Discriminant analysis}

Discriminant analysis was conducted using the methodology in section 2.4, producing two discriminant functions to classify individual cases into three groups. Table 10 shows the function statistics.

Table 10. Discriminant function statistics

\begin{tabular}{cccccccc}
\hline Function & Eigenvalue & $\begin{array}{c}\% \text { of } \\
\text { Variance }\end{array}$ & $\begin{array}{c}\text { Canonical } \\
\text { Correlation }\end{array}$ & Wilks' Lambda & Chi-square & df & $\begin{array}{c}\text { Sig. } \\
\mathrm{p}<0.05\end{array}$ \\
\hline 1 & 1.167 & 87.2 & 0.734 & 0.394 & 219.237 & 20 & 0.000 \\
2 & 0.171 & 12.8 & 0.382 & 0.854 & 37.092 & 9 & 0.000 \\
\hline
\end{tabular}

It can be seen that function 1 accounts for $87 \%$ of the variance and function 2 for the remaining $13 \%$. The canonical correlation statistics can be roughly translated into $\mathrm{R}^{2}$ statistics and suggest that overall, the model accounts for $68 \%\left(0.734^{2}+0.382^{2}\right)$ of variance in the dependent variable. Both functions are statically significant.

The variables included in the model are shown in Table 11. Along with their associated correlations with the two functions. The variables are highlighted in bold to show which function they have the strongest association with. 
Table 11. Discriminant analysis structure matrix and coefficients

\begin{tabular}{rrrrr}
\hline & Structure Correlations & \multicolumn{2}{c}{$\begin{array}{c}\text { Unstandardized } \\
\text { coefficients }\end{array}$} \\
& Function 1 & Function 2 & Function 1 & Function 2 \\
Demeanour & .653 & -0.15 & 1.597 & -0.469 \\
Observed Alcohol Intoxication & .515 & -0.179 & 1.159 & -0.317 \\
Reported Alcohol Consumption & .460 & -0.189 & 0.824 & -0.027 \\
Reported Mental Health Issues & .282 & 0.069 & 1.154 & -0.032 \\
Miscellaneous or Sexual Offence & -0.122 & -.538 & -0.001 & -1.517 \\
First time & 0.019 & .461 & 0.298 & 1.212 \\
Report Injury or Illness & 0.25 & .393 & 0.416 & 0.753 \\
Weekend & 0.302 & -.339 & 1.175 & -1.317 \\
Reported Self-harm & 0.281 & .331 & 0.618 & 0.838 \\
Reported Drug Use & 0.107 & .297 & 0.777 & 0.803 \\
(Constant) & & & -1.305 & -0.312 \\
\hline
\end{tabular}

The functions can also be shown graphically using the group means, or centroids, as shown in Figure 3.

Figure 3. Group centroids for the three observation levels

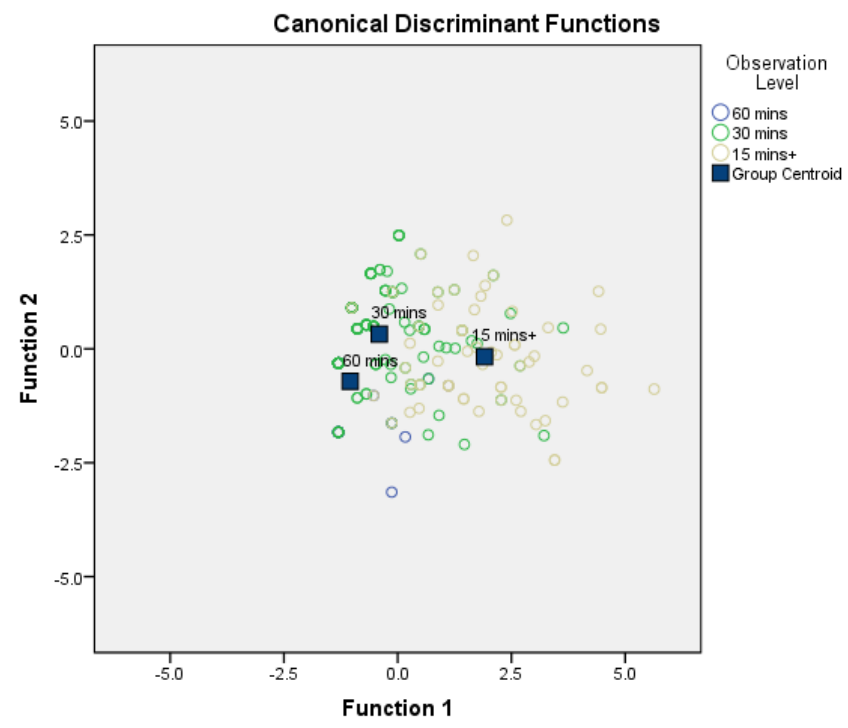

The group centroids in Figure 3 suggest that function 1 mainly separates the $60 \mathrm{~min}$ group from the $15 \mathrm{~min}$ group, whilst function 2 separates the $60 \mathrm{~min}$ group from the $30 \mathrm{~min}$ group. Visually, Figure 3 also suggests that there are greater differences in group means between the high-risk group (15minst) and the lower risk groups (60mins and $30 \mathrm{mins})$, than between the two lower-risk groups. The group centroids are also used to classify individual cases into groups, and the classification statistics are shown in Table 12. 
Table 12. Discriminant analysis classification statistics

\begin{tabular}{|c|c|c|c|c|c|}
\hline & \multirow[b]{2}{*}{ Observation Level } & \multicolumn{3}{|c|}{ Predicted Group Membership } & \multirow[b]{2}{*}{ Total } \\
\hline & & 60 mins & 30 mins & 15 mins+ & \\
\hline \multirow[t]{3}{*}{ Original } & 60 mins & 31.4 & 66.7 & 2.0 & 0.72 \\
\hline & 30 mins & 4.8 & 86.2 & 9.0 & \\
\hline & 15 mins+ & 1.6 & 26.2 & 72.1 & \\
\hline Cross- & 60 mins & 25.5 & 72.5 & 2.0 & 0.68 \\
\hline \multirow[t]{2}{*}{ validated } & 30 mins & 6.2 & 82.8 & 11 & \\
\hline & 15 mins+ & 1.6 & 27.9 & 70.5 & \\
\hline
\end{tabular}

Overall, $72 \%$ of cases were correctly classified, although this decreases slightly to $68 \%$ with crossvalidation. The group with the largest proportion accurately classified was $30 \mathrm{mins}(86 \%)$, followed by 15 mins $+(72 \%)$ and 60 mins which had the lowest proportion of $31 \%$. For this model $\mathrm{C}_{\text {pro25 }}$ was calculated as 0.52 , which is lower than both the original and cross-validated classification accuracy proportions.

\subsection{Combined results}

All three models returned a better than chance classification model, using only the most significant independent variables. The variables included in the three models are shown in Table 13.

Table 13. Independent variables included in the three modelling methods

\begin{tabular}{lccc}
\hline Variable & $\begin{array}{c}\text { Discriminant } \\
\text { Analysis }\end{array}$ & $\begin{array}{c}\text { Logistic } \\
\text { Regression }\end{array}$ & $\begin{array}{c}\text { Decision } \\
\text { Day of Week }\end{array}$ \\
First Time in Custody & $\checkmark$ & & $\checkmark$ \\
Observed Alcohol Intoxication & $\checkmark$ & $\checkmark$ & $\checkmark$ \\
Observed Demeanour & $\checkmark$ & $\checkmark$ & $\checkmark$ \\
Observed Self-Harm & $\checkmark$ & $\checkmark$ & $\checkmark$ \\
Offence & $\checkmark$ & $\checkmark$ & $\checkmark$ \\
Reported Alcohol Use & $\checkmark$ & $\checkmark$ & $\checkmark$ \\
Reported Drug Use & $\checkmark$ & $\checkmark$ & $\checkmark$ \\
Reported Feelings & & $\checkmark$ & $\checkmark$ \\
Reported Injury or Illness & $\checkmark$ & & \\
Reported Mental Health issues & $\checkmark$ & & \\
Reported Self-Harm & & $\checkmark$ & \\
Restraint Used & & $\checkmark$ & \\
\hline
\end{tabular}

When comparing the independent variables used in the three models, there appears to be a core group of driving factors which influence group classification. These are: Observed Alcohol Intoxication, Reported Alcohol Use, Reported Drug Use and Reported Mental Health Issues, which 
are included in all three models. There are also a further five variables which appear in two of the three models, and it could be argued that self-harm should also be included in this as both Reported Self-Harm and Observed Self-Harm are present in the discriminant analysis and decision tree models respectively.

\subsection{Summary of findings}

All three modelling methods provided a way of categorising cases into groups, with all achieving a similar level of overall classification accuracy of around $72 \%-73 \%$. In addition, all models accounted for a significant amount of variance, ranging from $63 \%$ for the logistic regression and decision tree models to $68 \%$ for the discriminant analysis model. These statistics suggest that using these models for classification is valid and that the methodology could be applied to a further dataset. This analysis suggests that there is a core group of up to ten independent variables which are driving factors as to what observation level is set.

\section{Discussion and further research}

The use of these statistical modelling methods has gleaned previously unknown knowledge on the most influential factors in determining a detainee's observation level and has produced a common set of independent variables which could be considered as driving factors. Comparing this core set with the risk factors identified through literature shows that they are similar. Alcohol and drug use, a key risk factor, appears in the core set of variables, with alcohol appearing twice through detainee reported use and custody officer observed intoxication. In addition, both mental health issues and injury or illness appear in the list, both of which have previously been identified as risk factors. This suggests that, given the data, the influence that these risk factors have on the observation level is appropriate. The presence of this commonality between models and identified risk factors indicates the foundations now for a tool that would support the decision-making process. These findings are pivotal in enabling and informing the development of such a tool that could be used in custody to support the risk assessment of detainees.

To enhance the methodology further, the statistical analysis could be applied to a larger dataset to explore the impact of demographic and socio-economic variables on risk as these did not feature in the current models but it is unclear as to whether this was influenced by missing data. As highlighted in the introduction, risk assessment content varies between forces (Stoneman et al. 2018) so further research should consider using data from different forces to examine whether the same variables are significant, or whether there are other variables captured by other forces, but not in this dataset, that would be included due to their association with Observation Level. In addition, any risk assessment is only as useful as the information on which it is based, and it is acknowledged that detainees may not always reveal personal information about risks. Research has also shown that the current risk assessment may miss a large proportion of risk and morbidity (McKinnon and Grubin, 2013).

The quantitative analysis of custody record data does not account for the custody officer's instinct or "feeling" about the risk of harm for the detainee. Often in decision-making individuals subconsciously refer to an "experiential system", which is intuitive and based on their own associations and experiences (Slovic et al., 2004, Dean and Gottschalk, 2007). This can be a fast, automatic process that the individual may not realise has influenced their decision making, and therefore 
difficult to calculate into the decision-making process. It is suggested that, to supplement these findings, qualitative research should be conducted with the aim of understanding the process from the custody officer's point of view. This would also help identify process steps that are not recorded in the data, for example identifying risks by looking at historical arrest records. Combining the findings from the quantitative analysis with those from the qualitative perspective will provide a fuller picture of the overall process.

Although what has been discussed in this paper is based on the initial risk assessment completed during the booking-in process, it is acknowledged that risk assessment also needs to be dynamic and consistent throughout the detainee's stay in custody. A detainee's emotional state is not static and can fluctuate depending on events throughout the journey, such as being charged or becoming sober (Wooff and Skinns, 2017). Therefore, another interesting angle for further research would be to conduct longitudinal analysis of the data to investigate how often the observation level is changed and any causes for the change.

Further research is also needed into whether the current risk assessment process used within England and Wales is robust and minimizes risk, and whether these variables identified as having the most influence on risk management and observation level are actually the most significant ones in predicting risk. With limited resources such as time, manpower and cell capacity it is essential to ensure that these are not being inefficiently allocated to detainees with a lower risk level, redirecting resources away from high risk detainees, endangering detainee safety.

\section{Conclusion}

In summary this analysis has provided the foundations for the creation of an evidence-based decision-support tool to aid custody staff in risk assessing detainees for harm to themselves or others. Currently, the process described in the national guidance does not provide a structured way of analysing and evaluating identified risk, meaning that the process is subjective and based on expert opinion rather than an actuarial assessment. This paper investigated what risk factors were most influential to the custody officer in deciding the risk treatment, or observation level, which to the authors' knowledge is the first time this has been carried out. These findings were then compared to risk factors highlighted in literature and investigative reports, as well as national guidance. The results showed that although the data identified the same influential risk factors as highlighted in literature, national guidance does not include questions around alcohol / drug use or withdrawal. With the most influential factors identified and further understanding through qualitative and longitudinal research, this research would enable the development of a risk assessment tool that would make the analysis and evaluation of detainee risk more robust. Such a structured decision-making model, which also incorporated officer experience and knowledge, would reduce variance in the assessment process, potentially reducing the number of occurrences where risk of harm to the detainee is realised.

\section{References}

Adams, S.T. \& Leveson, S.H., 2012. Clinical prediction rules. BMJ-British Medical Journal, 344. Angiolini, E., 2017. Report of the independent review of deaths and serious incidents in police custody. London: Home Office. 
Best, D., 2004. The Role of alcohol in police-related deaths : analysis of deaths in custody (Category 3) between 2000 and 2001 London: Police Complaints Authority.

Bucke, T., Teers, R., Menin, S., Payne-James, J.J. \& Stark, M., 2008. Near misses in police custody: A collaborative study with Forensic Medical Examiners in London. London: Independent Police Complaints Commission.

College of Policing, 2017. Detention and Custody Authorised Professional Practice [online]. College of Policing. Available from: http://www.app.college.police.uk/app-content/detention-andcustody-2/ [Accessed Access Date 30 Nov 2017].

Cummins, I., 2008. A place of safety? Self-harming behaviour in police custody. The Journal of Adult Protection, 10, 36-47.

De Oña, J., 2013. Extracting decision rules from police accident reports through decision trees. Accident Analysis and Prevention, 1151.

Dean, G. \& Gottschalk, P., 2007. Knowledge management in policing and law enforcement : foundations, structures, applications Oxford, UK: Oxford University Press.

Durodie, B., 2017. Theory informed by practice. Application informed by purpose. Why to understand and manage risk, cultural context is the key. Safety Science, 99, 244-254.

Hannan, M., Hearnden, I., Grace, K. \& Bucke, T., 2010. Deaths in or following police custody: An examination of the cases 1998/99 - 2008/09. London: Independent Police Complaints Commission.

Harris, G.T., Rice, M.E. \& Quinsey, V.L., 1993. Violent recidivism of mentally disordered offenders The development of a statistical prediction instrument. Criminal Justice and Behavior, 20, 315-335.

Havis, S., 2003. Drug-related deaths in police custody : a Police Complaints Authority study London: Police Complaints Authority.

Home Office, 2017. Code C Revised: Code of practice for the detention, treatment and questioning of persons by Police Officers: Police and criminal evidence act 1984 (PACE). London: Home Office.

Hosmer, D. \& Lemeshow, S., 2000. Applied Logistic Regeression, 2nd ed.: Wiley Interscience.

Howard, P.D. \& Dixon, L., 2012. The Construction and Validation of the OASys Violence Predictor. Criminal Justice and Behavior, 39, 287-307.

Ibm, 2013. IBM SPSS Decision Trees 22. USA: IBM Corporate.

Ibm Corp., Released 2015. IBM SPSS Statistics for Windows, Version 23.0. Armonk, NY: IBM Corp.

IOPC, 2018. Deaths during or following police contact: Statistics for England and Wales 2017/18. London: Independent Office of Police Conduct.

Kemshall, H., 1999. Risk assessment and risk managment: Practice and policy implications. The British Journal of Forensic Practice, 1, 27-36.

Lindon, G. \& Roe, S., 2017. Deaths in police custody: A review of the international evidence. UK: Home Office.

Mckinnon, I. \& Grubin, D., 2013. Health screening of people in police custody-evaluation of current police screening procedures in London, UK. The European Journal of Public Health, 23, 399405.

Monahan, J., Steadman, H.J., Appelbaum, P.S., Robbins, P.C., Mulvey, E.P., Silver, E., Roth, L.H. \& Grisso, T., 2000. Developing a clinically useful actuarial tool for assessing violence risk. British Journal of Psychiatry, 176, 312-319.

Norusis, M., 1999. SPSS : Regression Models 10.0 Upper Saddle River, N.J.: Prentice Hall.

Oswald, M., Grace, J., Urwin, S. \& Barnes, G., 2017. Algorithmic Risk Assessment Policing Models: Lessons from the Durham HART model and 'experimental' proportionality. Information \& Communications Technology Law, Forthcoming.

Pasman, H.J., Rogers, W.J. \& Mannan, M.S., 2017. Risk assessment: What is it worth? Shall we just do away with it, or can it do a better job? Safety Science, 99, 140-155. 
Payne-James, J., Green, P., Green, N., Mclachlan, G., Munro, M. \& Moore, T., 2010. Healthcare issues of detainees in police custody in London, UK. Journal of Forensic and Legal Medicine, 17, 1117.

Peng, C.-Y. \& Nichols, R., 2003. Using multinomial logistic models to predict adolescent behavioral risk. Journal of Modern Applied Statistical Methods, 2, 177-188.

Polanyi, M., 1958. Personal knowledge : towards a post-critical philosophy London: Routledge and Kegan Paul.

Police Leadership and Powers Unit, 2000. Detainee Risk Assessment \& revised Prisoner Escort Record (PER) form. In H. Office (ed.) http://library.college.police.uk/docs/hocirc/ho-circ2000-032-detainee-risk-assessment-and-PER.pdf: Home Office.

Slovic, P., Finucane, M.L., Peters, E. \& Macgregor, D.G., 2004. Risk as Analysis and Risk as Feelings: Some Thoughts about Affect, Reason, Risk, and Rationality. Risk Analysis, 24, 311-322.

Society for Risk Analysis, 2015. Society for Risk Analysis Glossary. In C.O.F.O.R. Analysis (ed.) Online: Society for Risk Analysis.

Society for Risk Analysis, 2017. Risk Analysis: Fundamental Principles. In C.O.F.O.R. Analysis (ed.) Online: Society for Risk Analysis.

Sondhi, A. \& Williams, E., 2017. Health needs and co- morbidity among detainees in contact with healthcare professionals within police custody across the London Metropolitan Police Service area. Journal of Forensic and Legal Medicine.

Song, Y.-Y. \& Lu, Y., 2015. Decision tree methods: applications for classification and prediction. Shanghai Archives of Psychiatry, 27, 130-135.

Spicer, J., 2004. Making sense of multivariate data analysis; An intuitive approach London: SAGE.

Steadman, H.J., Silver, E., Monahan, J., Appelbaum, P.S., Robbins, P.C., Mulvey, E.P., Grisso, T., Roth, L.H. \& Banks, S., 2000. A classification tree approach to the development of actuarial violence risk assessment tools. Law and Human Behavior, 24, 83-100.

Stoneman, M.-J., Jackson, L., Dunnett, S. \& Cooke, L., 2018. Variation in detainee risk assessment within police custody across England and Wales. Policing and Society: An International Journal of Research and Policy.

Tabachnick, B. \& Fidell, S., 2001. Using multivariate statistics, 4th ed. Boston, MA: Allyn and Bacon. The British Standards Institute, 2010. BS ISO 31000:2009 - Risk management. Principles and guidelines. British Standards. UK: British Standards Institute Limited.

Uk Parliament, 1984. Police and Criminal Evidence Act 1984. London: The Stationery Office.

Uk Parliament, 1998. Human Rights Act 1998. UK: The Stationery Office Ltd.

Uk Parliament, 2007. Corporate Manslaughter and Corporate Homicide Act 2007. Online: Her Majesty's Stationary Office.

White, J., 2013. Logistic regression Model Effectiveness: Proportional Chance Criteria and Proportional Reduction in Error. Journal of Contemporary Research In Education, 2, 4-10.

Wooff, A. \& Skinns, L., 2017. The role of emotion, space and place in police custody in England: towards a geography of police custody. Punishment \& Society, 0. 